\title{
Estudo Estratégico da Cadeia Produtiva da Indústria Cerâmica no Estado de São Paulo: Parte II - Indústria de Revestimentos
}

\author{
Marsis Cabral Junior ${ }^{a *}$, Paulo Brito Moreira de Azevedo ${ }^{\mathrm{b}}$, Gláucia Cuchierato ${ }^{\mathrm{c}}$, José Francisco Marciano Motta \\ ${ }^{a}$ Laboratório de Recursos Hídricos e Avaliação Geoambiental - LABGEO / Centro de Tecnologias Geoambientais / Instituto de \\ Pesquisas Tecnológicas do Estado de São Paulo - IPT, São Paulo, SP, Brasil.

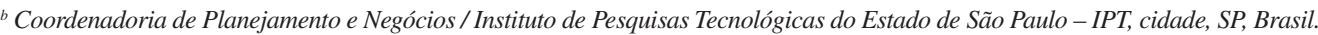 \\ ${ }^{c}$ GeoAnsata Projetos e Serviços em Geologia, cidade, UF, Brasil. \\ ${ }^{d}$ Consultor - Bolsista Fapesp \\ *e-mail: marsis@ipt.br
}

\begin{abstract}
RESUMO
Este trabalho deriva de estudo de maior abrangência dirigido à elaboração de um diagnóstico técnico-econômico da indústria cerâmica no estado de São Paulo, com vistas a subsidiar ações de governo que garantam o abastecimento sustentável de matérias-primas minerais a este setor da economia. Entre as cerâmicas tradicionais foram priorizados os segmentos industriais de maior relevância econômica no Estado e com consumo significativo de bens minerais, a saber: Cerâmica Vermelha, Revestimentos, Louça Sanitária, Louça e Porcelana - Mesa, Utilitários e Decoração, Colorifícios (Fritas, Esmaltes e Corantes), e Cerâmica Técnica - Isoladores Elétricos. Nesse contexto, as avaliações desses segmentos e a análise estratégica efetuadas buscaram estabelecer um arcabouço de informações, bem como sugestões de iniciativas para o fortalecimento do setor produtivo, que poderão auxiliar a formulação de políticas para modernização e aprimoramento do sistema de suprimento mineral ao parque cerâmico paulista.

Os principais resultados desse estudo estão sendo apresentados em uma série de quatro artigos. O primeiro, já publicado, abordou a contextualização e fatos motivadores do estudo, breve histórico e características gerais da indústria cerâmica no Estado, sendo tratada especificamente o segmento de cerâmica vermelha. Neste segundo artigo é analisada a indústria de revestimentos cerâmicos. Os demais segmentos industriais, bem como a análise estratégica da cadeia produtiva mínero-cerâmica, farão parte dos artigos subsequentes.
\end{abstract}

Palavras-Chave: cerâmica; matérias-primas, indústria; mineração; tecnologia

\section{INTRODUÇÃO}

Este trabalho decorre de estudo desenvolvendo pelo Instituto de Pesquisas Tecnológicas do Estado de São Paulo (IPT, 2018) e financiado pela Subsecretaria de Mineração da Secretaria de Energia e Mineração - SEM do Estado de São Paulo, que envolveu a elaboração de um diagnóstico técnico-econômico da indústria cerâmica no Estado de São Paulo, com a finalidade de coletar subsídios que permitam orientar ações de governo que garantam o abastecimento sustentável de matérias-primas minerais necessárias a este setor da economia, a curto, médio e longo prazo.

Contido nesse escopo geral, o desenvolvimento do estudo contemplou as seguintes metas:

a) caracterização qualitativa da estrutura de mercado e empresarial do elo central da cadeia produtiva cerâmica, isto é, do segmento de manufatura cerâmica, abrangendo os principais segmentos de manufatura cerâmica intensivos em consumo de minerais industriais, a saber: Cerâmica Vermelha, Revestimentos, Louça Sanitária, Louça e Porcelana de Mesa e Decorativa, Isoladores Elétricos e Colorifícios (fritas, esmaltes e corantes); b) projeções de consumo de bens minerais: estimativa de crescimento do parque cerâmico e da demanda derivada de insumos minerais, circunstanciada em três cenários de crescimento (pessimista, neutro e otimista); e

c) avaliação estratégica do setor cerâmico: indicações conclusivas sobre os principais fatores que interferem na competitividade da indústria cerâmica paulista e sugestão de diretrizes e ações para o aprimoramento competitivo, mormente relacionadas à demanda de bens minerais.

Os principais resultados desse estudo estão sendo apresentados em uma série de quatro artigos. O primeiro, já publicado, abordou a contextualização e fatos motivadores do estudo, breve histórico e características gerais da indústria cerâmica no Estado, sendo tratado especificamente o segmento de cerâmica vermelha (Cabral et al, 2019). Neste segundo artigo é analisado o segmento de revestimentos cerâmicos, buscando-se caracterizar a estrutura produtiva e empresarial, o sistema de suprimento mineral e as matérias-primas consumidas. 
Os demais segmentos industriais, bem como a análise estratégica da cadeia produtiva mínero-cerâmica, farão parte dos artigos subsequentes.

\section{A INDÚSTRIA DE REVESTIMENTOS CERÂMICOS NO BRASIL - BREVE HISTÓRICO}

O segmento de revestimentos engloba a produção de materiais cerâmicos no formato de placas usados na construção civil para revestimento de paredes, pisos, bancadas e piscinas, em ambientes internos e externos, recebendo designações comerciais como pastilha, porcelanato, grês, lajota, piso, etc.

A partir da base industrial de cerâmica vermelha estabelecida na primeira metade do Século XX, surgiram as primeiras fábricas de revestimento, inicialmente com a produção de ladrilhos hidráulicos e, posteriormente, azulejos e pastilhas cerâmicas.

$\mathrm{Na}$ sua primeira fase de desenvolvimento, a partir da década de 1960, a indústria de revestimento nacional esteve voltada para o mercado interno, uma vez que a demanda da construção civil absorvia, praticamente, toda sua produção.

Já na década de 1980, com a implantação do processo de queima rápida (monoqueima), o segmento passou por um novo surto de desenvolvimento consolidando os primeiros polos de produção situados nas regiões Sul e Sudeste.

Na década de 1990, na esteira do processo de abertura comercial da economia brasileira, houve um grande esforço de modernização das unidades fabris, o que permitiu um aumento importante da produção e melhoria da qualidade dos produtos. Nesta fase, já se realizava a exportação de alguns tipos de placas, sobretudo azulejos, e se iniciou a produção de porcelanatos. As exportações exigiram das empresas níveis de qualidade internacional e um grande esforço para a certificação de seus produtos.

Nas décadas de 1970 a 1980, as principais fábricas de revestimentos estavam localizadas na região Sul, principalmente em Santa Catarina, com algumas unidades instaladas em São Paulo e no Nordeste do Brasil. Fato notável a partir da década de 1990 foi o vertiginoso desenvolvimento do Polo de Santa Gertrudes no interior do Estado de São Paulo, que passou a liderar amplamente a produção brasileira nos anos 2000.

\section{TIPOLOGIA DE PLACAS CERÂMICAS E PROCESSO PRODUTIVO}

Vantagens dos revestimentos cerâmicos em relação a outros produtos substitutos são atribuídas à sua durabilidade, resistência mecânica, facilidade de limpeza e resistência ao ataque de líquidos, além de constituir um produto não inflamável, higienicamente inerte e inorgânico, e ter amplas possibilidades de padrões estéticos em sua superfície. A classificação dos revestimentos é feita segundo a absorção de água das placas cerâmicas, que influi diretamente em outras propriedades como resistência mecânica, resistência ao gelo e manchamento (Tabela 1).
Tabela 1 - Tipologia de placas cerâmicas.

\begin{tabular}{|c|c|c|}
\hline Grupo & $\begin{array}{c}\text { Absorção } \\
\text { de Água } \\
(\%)\end{array}$ & Aplicações Residenciais \\
\hline BIa & $0,0-0,5$ & $\begin{array}{l}\text { Pisos, Paredes - ambientes externos } \\
\text { e internos } \\
\text { (Porcelanato) }\end{array}$ \\
\hline BIb & $0,5-3,0$ & $\begin{array}{l}\text { Pisos, Paredes-ambientes externos } \\
\text { e internos } \\
\text { (Grês) }\end{array}$ \\
\hline BIIa & $3,0-6,0$ & $\begin{array}{l}\text { Pisos, Paredes - ambientes externos } \\
\text { e internos } \\
\text { (Semigrês) }\end{array}$ \\
\hline BIIb & $6,0-10$ & $\begin{array}{l}\text { Pisos, Paredes - ambientes externos } \\
\text { e internos } \\
\text { (Semiporoso) }\end{array}$ \\
\hline BIII & $>10$ & $\begin{array}{l}\text { Paredes } \\
\text { (Monoporosa / Azulejo) }\end{array}$ \\
\hline
\end{tabular}

Uma característica típica da produção brasileira, e única no cenário mundial do setor, é a utilização de dois processos produtivos distintos em seu parque industrial: a via seca e a via úmida (Figura 1).

Nas indústrias brasileiras de revestimento que operam por via seca utiliza-se a massa simples, constituída de argilas de queima avermelhada, cominuída em moinhos de martelo ou pendulares, levemente umidificada, e encaminhada ao processamento cerâmico (prensagem a seco, secagem, decoração e queima). Para a composição da massa há, geralmente, uma mistura de rocha argilosa fresca, mais fundente, com rocha parcialmente alterada, mais plástica. $\mathrm{O}$ grande produtor nacional deste tipo de revestimento é o polo paulista de Santa Gertrudes.

Os revestimentos obtidos por via úmida são de base preferencialmente de cor clara, formulados com massa composta, constituída de misturas de matérias-primas minerais (argilas, caulim, filito, rochas feldspáticas, talco, carbonatos, quartzo, entre outras). Essa mistura é moída e homogeneizada em moinhos de bola, em meio aquoso, seca e granulada em spray dryer (atomizador), e conformada por prensagem a seco, para seguir então para a decoração e queima. A seleção das matérias-primas busca dar cor branca ou clara à base dos produtos (biscoito ou suporte) e boa sinterização nas condições de queima rápida e temperaturas em torno de $1.200^{\circ} \mathrm{C}$. Para a produção do porcelanato, a seleção das matérias-primas é mais rigorosa, buscando-se intensificar a cor branca ou clara da base dos produtos (suporte) e boa sinterização nas condições de queima rápida ( 35 a 50 minutos) e temperaturas pouco acima de $1.200{ }^{\circ} \mathrm{C}$. Essa sinterização é possível com o aumento do conteúdo de feldspato que, além de aportar propriedades fundentes à massa, confere estabilidade durante a sinterização, permitindo a confecção de peças impermeáveis, com deformação controlada. No Brasil, a produção de revestimentos via úmida está concentrada em Criciúma (SC). 


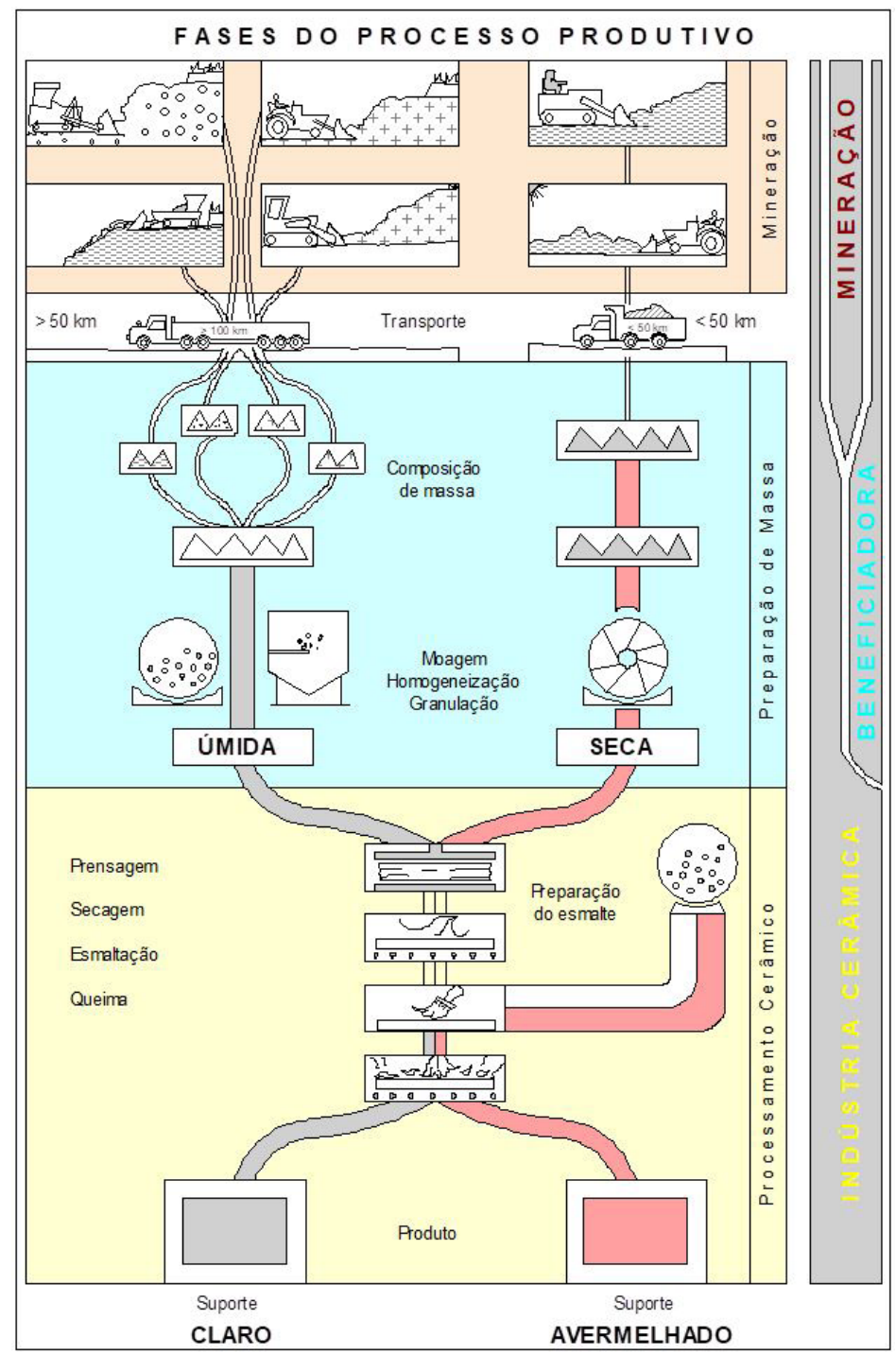

Figura 1 - Processo de produção de revestimentos cerâmicos. Fonte: extraído de Cabral Junior \& Serra (2006).

A indústria de revestimentos conta em sua matriz energética com o consumo de gás (essencialmente gás natural) no processo de combustão para atomização, secagem forçada das argilas e queima, e energia elétrica na movimentação dos equipamentos das plantas industriais.

\section{ESTRUTURA PRODUTIVA E EMPRESARIAL - CONTEXTO BRASILEIRO E PAULISTA}

O parque industrial brasileiro de revestimentos cerâmicos engloba cerca de 90 empresas, com de uma centena de plantas industriais e capacidade instalada de 1.050 milhões de $\mathrm{m}^{2}$ /ano em 2016 (Anfacer, 2018). Com instalações em 18 estados, tem a produção centralizada nas regiões Sudeste e Sul, onde estão localizados os principais arranjos produtivos locais - APLs de Santa Gertrudes (SP) e Criciúma (SC) - estando em franca expansão na região Nordeste. ${ }^{1}$ Trata-se de um segmento produtivo desconcentrado, de capital essencialmente nacional, no qual as principais empresas não alcançam $15 \%$ da produção nacional.

As vantagens competitivas que deram origem aos agrupamentos industriais brasileiros estão na combinação de três fatores: disponibilidade de fontes de matérias-primas qualificada, proximidade de mercados consumidores e capacitação local prévia de trabalhadores e empresários em setores correlatos, como a cerâmica vermelha (Cabral e Serra, 2006).

\footnotetext{
${ }^{1}$ A concentração geográfica é uma característica da indústria produtora de placas cerâmicas. Itália, Espanha e Brasil, maiores produtores ocidentais, têm sua indústria concentrada, respectivamente, nas regiões de Sassuolo, Castellón, Criciúma e Santa Gertrudes.
} 
No entanto, cada cluster desenvolveu-se em diferentes segmentos de mercado e explora diferentes vantagens competitivas. O APL de Criciúma desfruta da posição de liderança nacional em design e marcas, liderando as exportações em termos de valores comercializados. OAPL de Santa Gertrudes compete fundamentalmente em preços e oferece grande volume de produção, destinando seus produtos a segmentos populares de mercado.

O Brasil tem presença destacada no mercado mundial de revestimentos. Depois de consolidar-se como $2^{\circ}$ maior produtor e consumidor global a partir de meados da década passada, somente superado nos últimos 10 anos pelo imenso mercado chinês, a partir de 2016, em função da queda de sua produção e consumo, foi ultrapassado pela Índia. A produção brasileira alcançou seu pico em 2014, quando foram produzidos 900 milhões de $\mathrm{m}^{2}$ (Figura 2). Nos últimos três anos, houve um decréscimo paulatino, com a produção em 2017 situando-se em 790 milhões de m², o que corresponde a um decréscimo de mais de $12 \%$.

A indústria do Estado de São Paulo, que comanda a produção brasileira, teve um comportamento similar, alcançando seu patamar máximo de produção de 640 milhões de $\mathrm{m}^{2}$ no biênio 2014-2015. Derivada da perda do dinamismo da economia do país, a produção paulista teve uma queda de $14 \%$ nos últimos 2 anos (Figura 3).

Com uma produção de 554,7 milhões de $\mathrm{m}^{2}$ distribuídas em 51 plantas industriais, o Estado de São Paulo responde atualmente por $70 \%$ do total de placas cerâmicas fabricadas no Brasil. O restante da produção encontra-se concentrada na região Sul e Nordeste, que contam, respectivamente, com $18 \%$ e $12 \%$ do total de placas fabricadas em 2017 (Figura 4).

Situado na região centro-leste do Estado, o polo de Santa Gertrudes é responsável pela expressiva expansão da produção paulista e brasileira.

A sua grande vantagem competitiva é resultado do desenvolvimento de um processo industrial inovador fabricação via seca -, muito mais vantajosa economicamente do que a via úmida (processo tradicional utilizado mundialmente). Isto se deve ao fato dessa rota consumir apenas um tipo de matéria-prima (gastos menores na produção e transporte das substâncias minerais) e fazer uso de um processo industrial mais simples e menos dispendioso em consumo de energia térmica e elétrica. Os baixos custos permitiram que a aglomeração adotasse com larga vantagem uma estratégia competitiva por preços, e favorecida pela expansão da base da pirâmide de consumo no mercado brasileiro a partir de meados da década de 1990, obtivesse um crescimento vertiginoso por meio da venda de produtos populares, consolidando-se nos últimos anos como o principal polo produtor do hemisfério ocidental.

Esse diferencial competitivo associado aos custos de produção está vinculado diretamente ao recurso mineral existente na região, pois a partir de uma única fonte geológica são extraídas matérias-primas que se adaptam perfeitamente ao processo produtivo via seca, conseguindo-se obter um revestimento de boa qualidade. As argilas empregadas como matérias-primas possuem características especiais em termos de granulometria, assembleia mineralógica, baixo conteúdo de matéria orgânica, fácil secagem natural e alta fusibilidade, o que lhes conferem desempenho cerâmico praticamente único no cenário mundial.

As principais atividades produtivas desse cluster mínero-cerâmico estão concentradas dentro de um raio de $30 \mathrm{~km}$ a partir da área urbana de Santa Gertrudes e estendem-se aos municípios de Rio Claro, Cordeirópolis, Limeira, Ipeúna, Piracicaba e Araras (Figura 5). Atualmente, o polo congrega 34 cerâmicas que contam com equipamentos importados de tecnologia avançada. A escala de produção das fábricas pode ser considerada elevada em relação ao

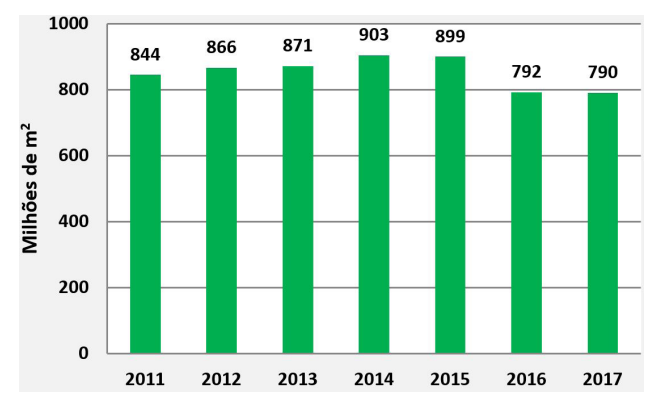

Figura 2 - Produção brasileira de placas cerâmicas - 2011 a 2017. Fonte: Anfacer (2018).

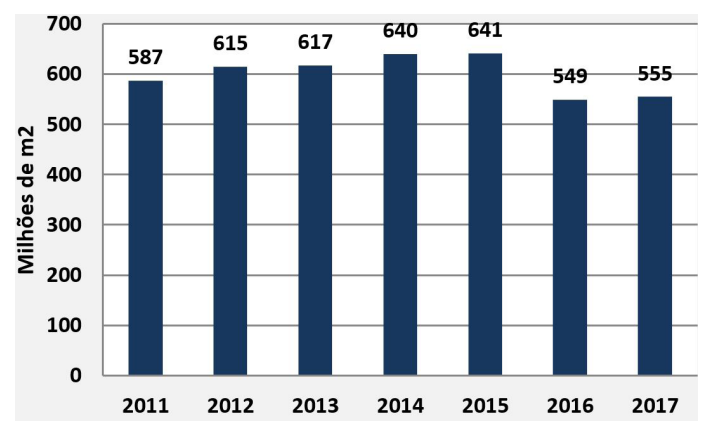

Figura 3 - Produção paulista de placas cerâmicas - 2011 a 2017. Fonte: Anfacer (2018).

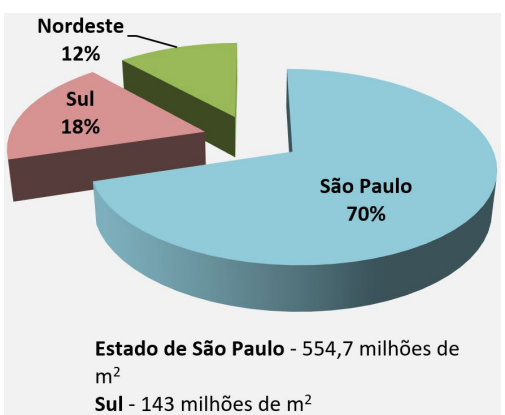

Figura 4 - Distribuição da produção brasileira de placas cerâmicas - 2017.

Fonte: Anfacer (2018). 


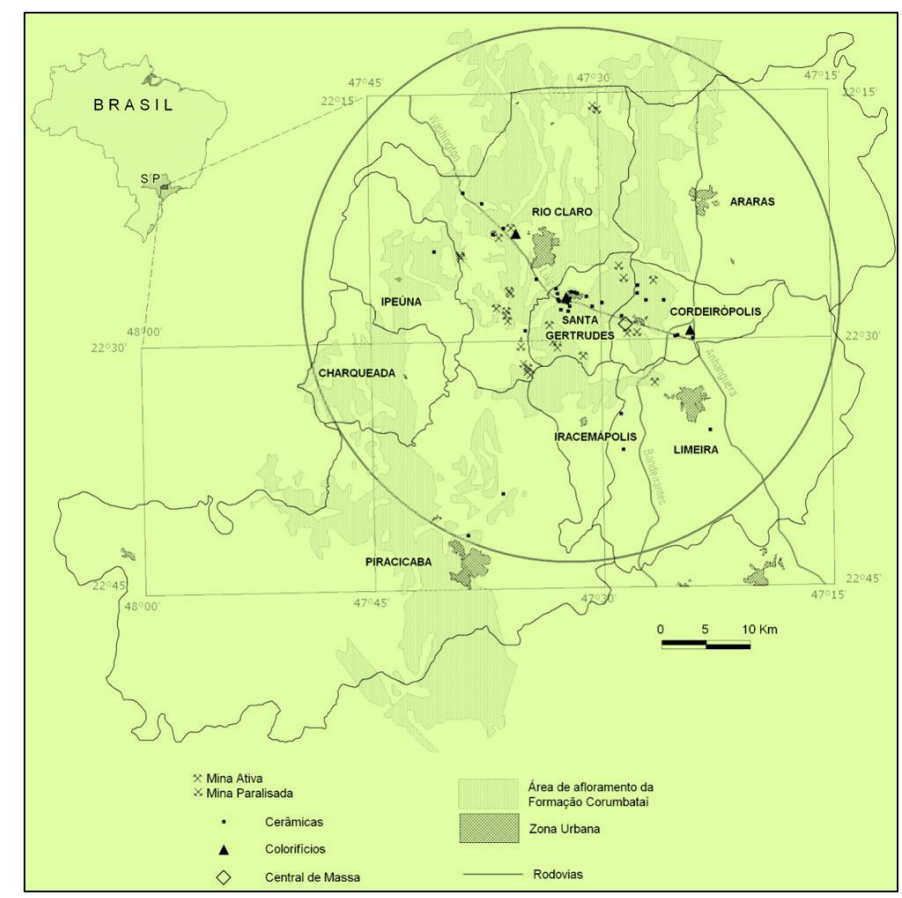

Figura 5 - Polo de Santa Gertrudes: perímetro de abrangência e distribuição das principais unidades produtivas.

Fonte: extraído de Cabral Junior, et al. (2013).

padrão internacional do segmento, com a maioria das plantas operando acima de $500 \mathrm{mil} \mathrm{m} /$ mês, sendo que mais de uma dezena tem capacidade instalada mensal superior a 1 milhão de $\mathrm{m}^{2}$.

Esse dinamismo do polo cerâmico tem provocado uma elevada e crescente demanda de matérias-primas minerais, cuja produção está territorialmente vinculada ao polo. Disso tudo se depreende que o desenvolvimento do Polo de Santa Gertrudes tem como um dos fatores fundamentais a continuidade do suprimento mineral a partir da fonte geológica situada em seu território.

\section{ESPECIALIZAÇÃO TECNOLÓGICA E TIPOLOGIA DE PRODUTOS}

Fato importante verificado no mercado brasileiro nessa última década é a tendência de especialização e concentração da produção em duas tipologias de produtos: placas semiporosas (Grupo BIIb) fabricadas por processo via seca e porcelanatos (BIa) por via úmida.

Observando-se a evolução do portfólio de produtos e os processos de fabricação envolvidos entre 2011 e 2017 (Figura 6), constata-se que é nítida a convergência da produção brasileira para esses duas tipologias de placas cerâmicas, o que vem acarretando na diminuição da produção das tradicionais placas tipo grês e semigrês pelo processo via úmida, fabricados principalmente nas plantas industriais da região Sul.

Diferentemente do abastecimento das indústrias de cerâmica vermelha, cujo perfil produtivo e a tipologia de matérias-primas são similares em todo território brasileiro,

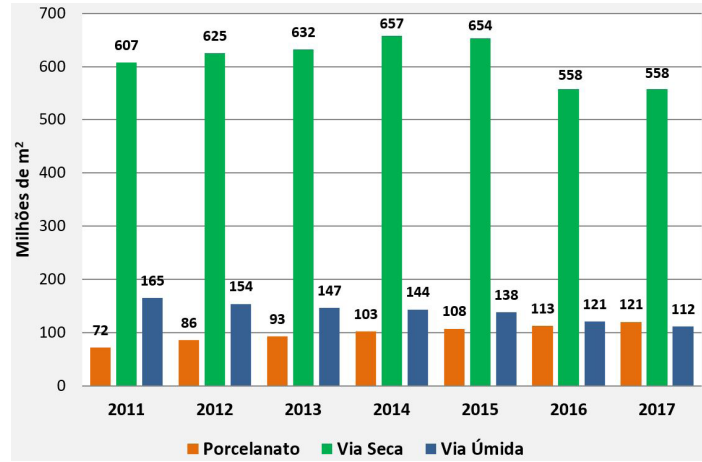

Figura 6 - Segmentação do mercado brasileiro - 2001 a 2017. Fonte: Anfacer (2018).

a diferenciação de processo e tipologia de produtos das principais regiões produtoras de revestimentos (Figura 7) tem como consequência formulações de massas específicas e distintas matrizes de insumos minerais consumidos.

No caso do mercado produtor paulista, que cresceu exclusivamente a partir dos produtos Via Seca, constata-se a rápida expansão das placas porcelânicas nesta última década, mormente pelo processo via úmida (Tabela 2).

Se em primeiro momento a fabricação de placas porcelanizadas ainda é pouco expressiva em relação ao total produzido no Estado (menos de $10 \%$ ), a diferente matriz de insumos minerais consumidos na sua fabricação já traz impacto importante no sistema de abastecimento mineral. 
Tabela 2 - Segmentação do mercado paulista: produção (milhões de m²) - 2011 a 2017.

\begin{tabular}{lrrrrrrr}
\hline & $\mathbf{2 0 1 1}$ & $\mathbf{2 0 1 2}$ & $\mathbf{2 0 1 3}$ & $\mathbf{2 0 1 4}$ & $\mathbf{2 0 1 5}$ & $\mathbf{2 0 1 6}$ & \multicolumn{2}{c}{$\mathbf{2 0 1 7}$} \\
\hline Porcelanato - Via Seca & 2,32 & 7,13 & 6,83 & 6,73 & 6,38 & 6,70 & 6,39 \\
Porcelanato - Via Úmida & 16,70 & 21,12 & 21,02 & 25,23 & 26,88 & 33,59 & 41,38 \\
Cerâmica & 567,99 & 586,89 & 588,85 & 608,37 & 607,50 & 509,08 & 506,93 \\
TOTAL & $\mathbf{5 8 7 , 0 0}$ & $\mathbf{6 1 5 , 1 3}$ & $\mathbf{6 1 6 , 7 0}$ & $\mathbf{6 4 0 , 3 3}$ & $\mathbf{6 4 0 , 7 6}$ & $\mathbf{5 4 9 , 3 7}$ & $\mathbf{5 5 4 , 6 9}$ \\
\hline
\end{tabular}

Fonte: Aspacer (2018).

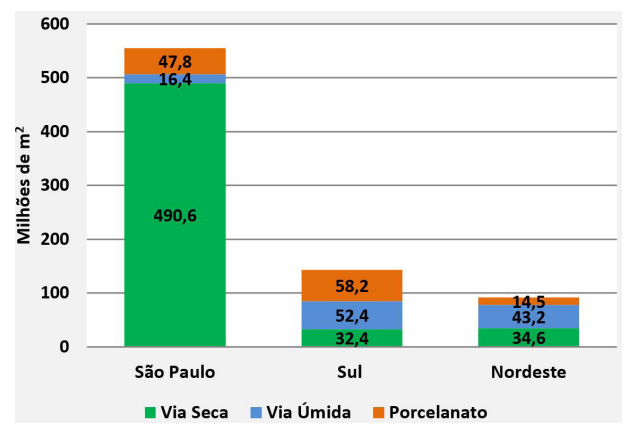

Figura 7 - Distribuição da produção brasileira por tipologias de placas cerâmicas -2017 .

Fonte: Anfacer (2018).

\section{SISTEMA DE SUPRIMENTO MINERAL}

Como abordado anteriormente, enquanto os produtos via seca são produzidas a partir de massa monocomponente, constituída de argilas de queima avermelhada ("argila comum"), as placas fabricadas pelo processo via úmido são de base preferencialmente de cor clara, formulados com massa composta, constituída de mix de matérias-primas minerais, que reúnem materiais fundentes, inertes e formadores de vidro.

Como consequência, o mercado produtor mineral que abastece esses duas modalidades de plantas industriais possui características distintas quanto aos tipos de jazidas e o ao perfil empresarial dos mineradores.

\subsection{Características das Matérias-Primas e do Mercado Produtor Mineral para as Indústrias de Revestimento Via Seca}

Como acontece também com o sistema de suprimento do setor de cerâmica vermelha, os custos de transação relativamente elevados (insumo específico de baixo valor unitário frente aos custos elevados para a consolidação de um mercado produtor) induzem à produção verticalizada de argila pelas indústrias de revestimentos via seca, não havendo, praticamente, um mercado estabelecido ofertante de matérias-primas. Prevalecem, portanto, minas cativas. Cerâmicas detentoras de jazidas mais expressivas comercializam excedentes, sendo que pequena fatia do mercado (menos que $20 \%$ ) é abastecido por mineradores. As jazidas situam-se praticamente junto ao parque fabril, com distância de transporte não excedendo a $30 \mathrm{~km}$.

Uma diferenciação importante entre as minerações de argila formacional que suprem a indústrias de revestimentos e as de cerâmica vermelha refere-se ao porte dos empreendimentos, sempre muito maiores no primeiro caso, com escalas de produção mensal situando-se entre 20.000 e 80.000 toneladas.

No Polo de Santa Gertrudes, o grande destaque em termos de fonte de matérias-primas para os produtos via seca refere-se ao conjunto lítico da Formação Corumbataí, unidade permiana da Bacia do Paraná, que se traduz na principal vocação mínero-industrial da região. A matéria-prima utilizada é constituída essencialmente por siltitos maciços e laminados, e intercalações de siltitos com argilitos, folhelhos e arenitos finos de cores variadas, inseridos em uma sequência sedimentar que chega a alcançar cerca de 100 metros de espessura. Quase toda essa coluna litológica da Formação Corumbataí pode ser utilizada na fabricação de produtos cerâmicos, sendo que suas características composicionais e as propriedades tecnológicas apresentam significativa variação tanto na vertical como na horizontal. As rochas pelíticas utilizadas possuem teores elevados de óxidos fundentes, o que faz com que os produtos obtenham propriedades adequadas de resistência e porosidade a temperaturas de queima relativamente baixas (em torno de 1.050 a $1.100^{\circ} \mathrm{C}$ ), com um ciclo de queima inferior a 25 minutos, abaixo do ciclo médio do processo via úmida que é de 30 a 40 minutos.

Pelas informações disponíveis, os atributos especiais da Formação Corumbataí - alta qualificação dos litotipos como matéria-prima cerâmica, possança dos pacotes e reservas expressivas, estão concentrados na região do Polo de Santa Gertrudes, cobrindo parte dos territórios dos municípios de Piracicaba, Charqueada, Ipeúna, Iracemápolis, Limeira, Cordeirópolis, Santa Gertrudes, Rio Claro e Araras.

O desempenho cerâmico dessa unidade é produto de complexa interação de múltiplos processos que atuaram durante a sedimentação (no ambiente original da deposição sedimentar), a diagênese (fase de soterramento e compactação da pilha sedimentar, com aumento de temperatura e pressão, percolação de fluidos, provocando transformações mineralógicas e texturais das rochas) e, mais recentemente, pela exposição superficial da unidade (alterações intempéricas, causando mudanças mineralógicas e texturais). O êxito das matérias-primas da Formação Corumbataí para a produção de revestimentos via seca está relacionado à composição mineralógica e textural dos litotipos, ressaltando a pequena quantidade de quartzo detrítico (inferior a 25\%), com dimensões normalmente inferiores a $120 \mu \mathrm{m}$, amplo predomínio de illita entre os 
Quadro 1 - Atividades envolvidas na produção de argila e massas cerâmicas.

\begin{tabular}{|c|c|}
\hline Atividades Essenciais & Etapas \\
\hline - Pesquisa mineral & $\begin{array}{l}\text { Etapa de quantificação e qualificação da jazida na fase de } \\
\text { legalização do empreendimento }\end{array}$ \\
\hline - Remoção da cobertura vegetal & \multirow{8}{*}{$\begin{array}{l}\text { Etapa de desenvolvimento da mina: lavra beneficiamento } \\
\text { e estocagem da argila }\end{array}$} \\
\hline - Decapeamento & \\
\hline - Desmonte & \\
\hline - Carregamento e transporte & \\
\hline - Estocagem intermediária (pilha pulmão e sazonamento) & \\
\hline - Destorroamento & \\
\hline - Trabalhos de pátio & \\
\hline - Estoque & \\
\hline - Moagem & \multirow{2}{*}{ Etapa de composição da massa cerâmica } \\
\hline - Umidificação e granulação & \\
\hline
\end{tabular}

filossilicatos (média ao redor de $50 \%$ ) e a significativa presença de albita diagenética (média ao redor de 30\%).

A produção de argila corresponde destacadamente ao principal segmento da indústria mineral na região centro-leste do Estado, representado por um número substancial de minas (cerca de 30 em operação), pátios de secagem, homogeneização e estocagem (pilhas a céu aberto e galpões - mais de 40), a maior parte constituindo empreendimentos isolados, e unidades de cominuição (britadores e moinhos). ${ }^{2}$

Embora o desenvolvimento de um projeto de mineração não empregue um método sistemático e único para todos os empreendimentos, há um conjunto de atividades essenciais que são comuns ao sistema produtivo e de suprimento de matérias-primas no Polo Cerâmico de Santa Gertrudes, como sintetizado no Quadro 1 e parcialmente ilustrado na Figura 8.

O método de lavra de argila utilizado na região é tradicional e relativamente simples minas a céu aberto com avanço da lavra através de uma ou mais cavas secas, que chegam a atingir algumas dezenas de metros. Inicialmente, a lavra pode se desenvolver em encosta, porém, devido à baixa declividade do terreno (geralmente entre 5 e 10\%), com o avanço da extração, rapidamente passa-se a configurar a lavra em cava. O desmonte normalmente é feito por escavação mecânica. Quando o minério apresenta-se compactado e muito duro podem ser necessárias operações de desmonte com explosivos.

A lavra é geralmente realizada de forma seletiva, procurando-se diferenciar as variações composicionais das camadas argilosas encontradas nas jazidas, permitindo

\footnotetext{
${ }^{2}$ A consolidação quantitativa da estrutura produtiva constitui uma referência de momento, pois a atividade mineral é bastante dinâmica na região, notadamente em função dos mercados produtor e consumidor de argilas, ocorrendo frequentes paralisações, retomadas e entrada de novos empreendimentos em operação. Essa dinâmica produtiva depende de vários fatores, entre outros, de condições de mercado (p.ex. ofertante com matéria-prima de melhor qualidade e/ou em melhor situação de logística) e do processo de legalização das jazidas.
}

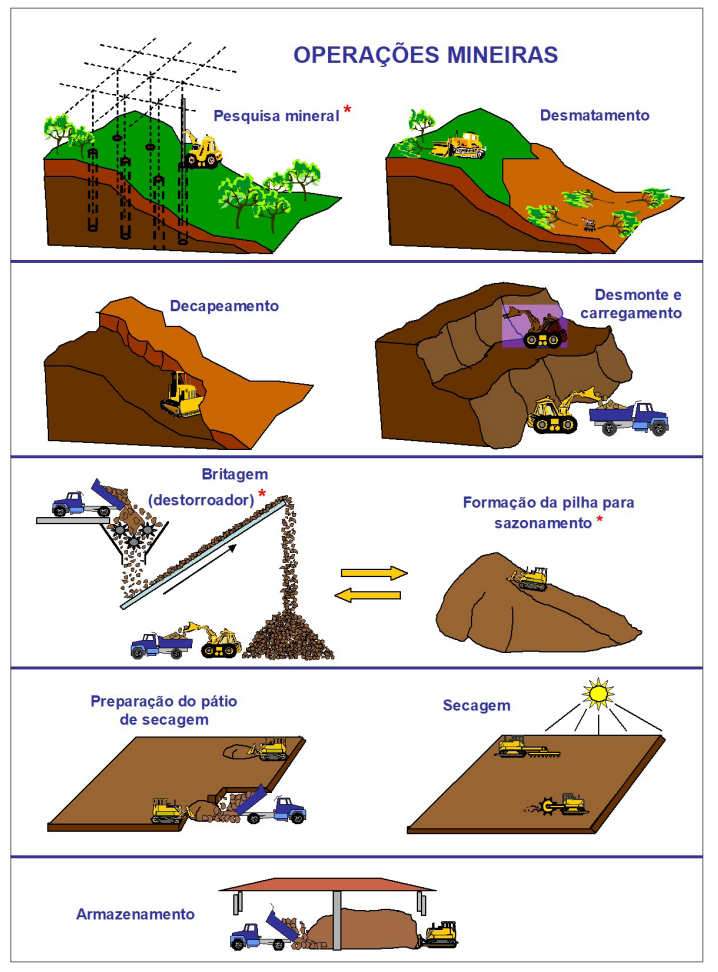

Figura 8 - Ciclo básico de produção (CBP) de argila no Polo de Santa Gertrudes.

Obs. * operações realizadas por algumas empresas. Fonte: extraído de IPT (2005).

efetuar posterior blendagem das matérias-primas destinadas às indústrias cerâmicas, o que é essencial para o controle do processo de fabricação do revestimento cerâmico. O desenvolvimento da maioria das minas é feito de forma empírica, com carência de conhecimentos sistemáticos sobre a geologia e as características tecnológicas e quantitativas das jazidas.

Das cavas, após a operação de desmonte, sucede-se o transporte da argila por caminhões até pátios não cobertos, 
Quadro 2 - Contexto geológico das matérias-primas cerâmicas utilizadas na indústria de revestimento via úmida.

\begin{tabular}{|l|l|}
\hline \multicolumn{1}{|c|}{ MATÉRIA PRIMA } & \multicolumn{1}{c|}{ TIPO DE DEPÓSITO } \\
\hline $\begin{array}{l}\text { Argilas plásticas de } \\
\text { queima clara }\end{array}$ & $\begin{array}{l}\text { - Lentes pequenas a médias em planícies aluvionares quaternárias } \\
\text { - Mais restritamente, camadas alteradas e lixiviadas em bacias sedimentares (alteritas) }\end{array}$ \\
\hline Caulim & $\begin{array}{l}\text { - Bolsões intemperizados em pegmatitos } \\
\text { - Manto de intemperismo de rochas cristalinas - granitóides e vulcânicas ácidas } \\
\text { - Manto de intemperismo de rochas sedimentares }\end{array}$ \\
\hline Feldspato & $\begin{array}{l}\text { - Pegmatito (rocha com bolsões de megacristais de feldspato potássico e albita) } \\
\text { - Maciços cristalinos - feldspatos e feldspatóides em rochas granitóides e alcalinas }\end{array}$ \\
\hline Filito & - Seqüências metassedimentares de idade pré-cambriana \\
\hline Talco & $\begin{array}{l}\text { - Bolsões e camadas associadas a seqüências metassedimentares dolomíticas e a corpos } \\
\text { ultramáficos pré-cambrianos }\end{array}$ \\
\hline Rochas Carbonáticas & $\begin{array}{l}\text { - Depósitos estratiformes em bacias metassedimentares; de forma subordinada, em bacias } \\
\text { sedimentares }\end{array}$ \\
\hline Bentonita Branca & - Camadas argilosas associadas a cinzas vulcânicas em bacias sedimentares \\
\hline Sílica & $\begin{array}{l}\text { - Depósitos de areia quartzosa em bacias sedimentares paleozóicas e cenozóicas } \\
\text { - Lentes e camadas de quartzitos pré-cambrianos } \\
\text { - Veios de quartzo no embasamento cristalino e em bolsões de pegmatitos }\end{array}$ \\
\hline
\end{tabular}

onde é promovida secagem e pré-homogeneização do material, com tratores adaptados de grades e rolos. Opcionalmente também se realiza o destorroamento dos blocos em britador de martelos ou rolos. Posteriormente o material manuseado é encaminhado para galpões cobertos onde se realiza a homogeneização final e a estocagem da matéria-prima, visto que há sazonalidade climática na lavra.

\subsection{Característica das Matérias-Primas e do Mercado Produtor Mineral para as Indústrias de Revestimentos Via Úmida}

Diferentemente do abastecimento mineral das fábricas de revestimentos via seca, realizado a partir de minerações preponderantemente cativas situadas dentro do Polo de Santa Gertrudes, para as linhas de produção via úmida há um elo mineral individualizado dentro da cadeia produtiva cerâmica.

Nesse caso, o suprimento de matérias-primas está desvinculado do território do APL de Santa Gertrudes, com as minerações situando-se em outras regiões do Estado e, dependendo do tipo de matéria-prima, sendo proveniente de outras unidades da federação.

As matérias-primas e as respectivas quantidades consumidas dependem da composição das massas cerâmicas que é uma particularidade de cada planta industrial. Por sua vez, a formulação das massas é função, basicamente, do tipo de processo empregado, dos produtos manufaturados e da oferta de substâncias minerais. Entre as principais variedades de substâncias minerais empregadas estão: argilas plásticas de queima clara, caulins, filitos, feldspatos e rochas feldspáticas (granito, fonolito, nefelina sienito), talco, rochas carbonáticas e quartzo. O Quadro 2 sintetiza o contexto geológico dos principais minerais industriais cerâmicos demandados pela segmento de revestimento via úmida.

Característica importante do sistema de suprimento mineral das indústrias via úmida é que o mercado produtor é mais abrangente abastecendo também outros setores da indústria cerâmica nacional como de sanitários, louça de mesa e colorifícios. Empresarialmente, constituem mercados desconcentrados, constituído em sua maioria de pequenas e médias empresas, de capital nacional. Parcela do suprimento é proveniente de outros estados, casos, em parte ou totalmente, do feldspato e rochas feldspáticas, caulim, talco, rochas carbonáticas e filito.

A matriz de insumos minerais e o seu compartilhamento entre os diversos setores cerâmicos consumidores é apresentado no Item 7 deste Relatório.

\subsection{Estimativa de Consumo de Minerais Industriais Cerâmicos}

Analisando-se de forma agregada, a indústria de revestimento no Estado consome volumes expressivos de substâncias minerais, movimentando, anualmente, cerca de 9,2 milhões de toneladas, sendo 7,9 milhões de toneladas nas indústrias de processo Via Seca e 1,3 milhão de toneladas no segmento Via Úmida (Tabela 3).

A Tabela 4 apresenta o consumo anual de substâncias minerais pela indústria de revestimento, segmentado por massas processadas seca, úmida e de porcelanato. esmaltado e técnico ${ }^{3}$. Trata-se de uma estimativa baseada nos dados

\footnotetext{
${ }^{3}$ No mercado há dois tipos de porcelanato: técnico e esmaltado. O técnico é composto somente pela massa cerâmica, sendo que a coloração e a padronagem são definidas por corantes aplicados na própria composição da massa, com acabamentos superficiais aplicados diretamente sobre a própria placa porcelanizada. O esmaltado, como a designação comercial evidencia, recebe uma camada de esmalte que lhe confere as características estéticas. Ambos são fabricados por processo similar via úmida, mas com importantes diferenças na composição de matérias-primas. O porcelanato técnico exige matérias-primas mais puras (argilas e caulim com baixo teor de óxidos corantes) e tem como principal fundente o feldspato, enquanto o esmaltado fabricado nas plantas de São Paulo contém elevado conteúdo de filito.
} 
Tabela 3 - Consumo de matérias-primas minerais na indústria de revestimentos cerâmicos - ano base 2017.

\begin{tabular}{lccc}
\hline \multicolumn{1}{c}{ Matérias-Primas } & \multicolumn{2}{c}{ Processo } & \multirow{2}{*}{ Total / Ano } \\
\cline { 2 - 3 } Consumo de Minerais & "Via Seca" & "Via Úmida" & \\
\hline Consumo de Massa $\left(\mathrm{kg} / \mathrm{m}^{2}\right)$ & 14,0 & 18,9 & $\mathbf{9 . 2 3 3 . 0 8 8}$ \\
\hline Total / ano (toneladas) & $\mathbf{7 . 8 9 8 . 6 6 0}$ & $\mathbf{1 . 3 3 4 . 4 2 8}$ & \\
\hline
\end{tabular}

Fonte: baseado em dados de produção de revestimentos fornecidos pela Anfacer e Aspacer (2018).

Tabela 4 - Consumo mineral na indústria de revestimentos cerâmicos desagregado por substância - ano base 2017.

\begin{tabular}{|c|c|c|c|c|c|c|}
\hline \multirow{2}{*}{ Substância Mineral } & & \multicolumn{4}{|c|}{ Processo } & \multirow{2}{*}{$\begin{array}{c}\text { Total } \\
\text { toneladas } \mathrm{x} \\
1.000\end{array}$} \\
\hline & & $\begin{array}{c}\text { Massa Via } \\
\text { Seca } \\
\end{array}$ & $\begin{array}{c}\text { Massa Via } \\
\text { Úmida }\end{array}$ & $\begin{array}{c}\text { Porcelanato } \\
\text { Esmaltado }\end{array}$ & $\begin{array}{c}\text { Porcelanato } \\
\text { Técnico } \\
\end{array}$ & \\
\hline \multirow{2}{*}{$\begin{array}{l}\text { Argilas Fundentes } \\
\text { Vermelhas }\end{array}$} & $\%$ & 100 & - & - & & \\
\hline & toneladas $\mathrm{x} 1.000$ & 7.898 .660 & & & & 7.898 .660 \\
\hline \multirow{2}{*}{$\begin{array}{l}\text { Argilas Plásticas } \\
\text { de Queima Clara }\end{array}$} & $\%$ & & 35 & 40 & 35 & \\
\hline & toneladas $\mathrm{x} 1.000$ & & 115.518 & 343.013 & 75.034 & 533.565 \\
\hline \multirow{2}{*}{ Caulim } & $\%$ & & 5 & 6 & 10 & \\
\hline & toneladas $\mathrm{x} 1.000$ & & 16.503 & 51.452 & 21.438 & 89.393 \\
\hline \multirow{2}{*}{ Filito } & $\%$ & & 45 & 45 & 5 & \\
\hline & toneladas $\mathrm{x} 1.000$ & & 135.068 & 352.334 & 9.787 & 497.189 \\
\hline \multirow{2}{*}{ Feldspato } & $\%$ & & & & 45 & \\
\hline & toneladas $\mathrm{x} 1.000$ & & & & 84.728 & 84.728 \\
\hline \multirow{2}{*}{$\begin{array}{l}\text { Talco, Calcário, } \\
\text { Dolomito, Quartzo }\end{array}$} & $\%$ & & 15 & 8 & 3 & \\
\hline & toneladas $\mathrm{x} 1.000$ & & 49.508 & 68.603 & 6.431 & 124.542 \\
\hline \multirow{2}{*}{ Bentonita } & $\%$ & & & 1 & 2 & \\
\hline & toneladas $\mathrm{x} 1.000$ & & & 835 & 4.176 & 5.011 \\
\hline Total & toneladas $\mathrm{x} 1.000$ & 7.898 .660 & 316.597 & 816.237 & 201.594 & 9.233.088 \\
\hline
\end{tabular}

Fonte: elaborado a partir de informações da produção de revestimentos cerâmicos da Anfacer e Aspacer.

de produção de revestimentos fornecidos pela Anfacer e Aspacer para os estudos deste projeto.

Destacam-se pelas quantidades consumidas argilas comuns fundentes, empregadas como matéria-prima essencial dos revestimentos via seca, argilas plásticas de queima clara, filitos, caulins e feldspato para os revestimentos via úmida. $\mathrm{O}$ feldspato e a bentonita branca são consumidos basicamente no porcelanato, sendo que, ocasionalmente, em massas superbrancas é adicionada também pequena porcentagem de zirconita.

Por envolver, na maioria dos casos, bens minerais de baixo valor unitário, o abastecimento das plantas é regionalizado, buscando-se fontes de matérias-primas mais próximo possíveis, de modo a diminuir o custo de transporte.

\section{REFERÊNCIAS}

ANFACER - ASSOCIAÇÃO NACIONAL DOS FABRICANTES DE CERÂMICA DE REVESTIMENTOS. Informações fornecidas ao IPT (inédito). 2018

ASPACER - A SSOCIAÇÃO PAULISTA DAS CERÂMICAS DE REVESTIMENTOS. Informações fornecidas ao IPT (inédito). 2018.
CABRAL JUNIOR, M.; SERRA, N. (Coord.) Bases para implantação de um Polo Mínero-Cerâmico no Estado da Bahia. Salvador: CBPM, 2006. 132 p.

CABRAL JUNIOR, M.; GAMBA, T. de C.; TANNO, L. C.; ALMEIDA, A. S.; Cruz, T. T de. Potencial das reservas de argila para o suprimento do polo cerâmico de Santa Gertrudes - SP: onde o recurso mineral faz a diferença. Cerâmica Industrial, v. 18, n. 2, p.10 - 16, 2013.

CABRAL JUNIOR, M.; AZEVEDO, P. B. M. de; CUCHIERATO, G.; MOTTA, J. F. M. Estudo Estratégico da Cadeia Produtiva da Indústria Cerâmica no Estado de São Paulo: Parte I Introdução e a Indústria de Cerâmica Vermelha. Cerâmica Industrial, v. 24, n. 1, p. 20 - 34, 2019.

IPT - INSTITUTO DE PESQUISAS TECNOLÓGICAS DO ESTADO DE SÃO PAULO. Aprimoramento da produção de matérias-primas com vistas à melhoria da competitividade do arranjo produtivo do setor mínerocerâmico na região de Santa Gertrudes - Rio Claro (SP). São Paulo: IPT, 2005. (Rel. n. 72 724-205).

IPT - INSTITUTO DE PESQUISAS TECNOLÓGICAS DO ESTADO DE SÃO PAULO. Estudo estratégico da cadeia produtiva da indústria cerâmica no Estado de São Paulo - Fase 1. São Paulo: IPT, 2018. (Rel. n. 153900-205). 